\title{
Myringotomy with versus without grommet tube insertion in chronic serous otitis media with effusion : Southern Oman experience
}

\author{
Original \\ Article \\ Hazem M. Abdel Tawab \\ Department of Otorhinolaryngology, Sultan Qaboos Hospital, Salalah, Oman and Department \\ of Otorhinolaryngology, Faculty of Medicine, Cairo University, Egypt.
}

\begin{abstract}
Objective: Otitis media with effusion (OME) can lead to hearing loss and delayed speech. Adenoidectomy with myringotomy and ventilation tube insertion are used in the management of OME. This study aimed to compare outcomes of myringotomy with versus without grommet tube insertion in children with OME in Southern Oman.

Patients and Methods: A prospective randomized study of 74 patients with serous OME, divided into 2 equal groups, was conducted over 2 years. Group A patients underwent adenoidectomy with myringotomy and grommet tube insertion, while only adenoidectomy and myringotomy were performed on patients in group B. Average age, gender, preoperative hearing loss and postoperative hearing gain, tympanometry 9 months after the operation, and incidence of otorrhoea and myringosclerosis were compared.

Results: All the parameters showed a nonsignificant statistical difference. Otorrhoea and myringosclerosis incidence was higher in group A, with a significant statistical difference.

Conclusion: Myringotomy alone showed favourable results with fewer complications in treatment of serous OME.

Key Words: Otitis media with effusion, myringotomy, grommets, adenoidectomy, myringosclerosis.

Received: 12 September 2019, Accepted: 14 February 2020

Corresponding Author: Hazem M. Abdel Tawab, Department of Otorhinolaryngology, Sultan Qaboos Hospital, Salalah, Oman and Department of Otorhinolaryngology, Faculty of Medicine, Cairo University, Egypt. Tel.: : 0096891128430, E-mail: hazemabdeltawwab77@yahoo.com.
\end{abstract}

ISSN: 2090-0740, July 2020 Vol.21, No. 2

\section{INTRODUCTION}

Otitis media with effusion (OME) is a common problem of childhood, caused by acute or chronic inflammation of the middle ear cleft. It is characterized by the collection of non-purulent fluid behind the intact ear drum ${ }^{[1]}$. There are different causes for the development of OME, but Eustachian tube dysfunction remains the commonest and most important reason for this condition ${ }^{[2]}$.

Leaving this condition untreated might lead to serious outcomes in the paediatric population, such as hearing loss, delayed speech, retraction pockets, and cholesteatoma ${ }^{[1]}$.

Approximately $90 \%$ of preschool children might have otitis media with effusion, with higher incidence between 6 months and 4 years of age ${ }^{[3]}$.

OME is the commonest cause of diminished hearing as well as surgeries in the childhood period ${ }^{[4]}$.

At the start of disease pathogenesis, the fluid in the middle ear is serous in consistency; it then develops a seromucinous and mucoid consistency due to goblet cell metaplasia before ultimately changing into a glue-like material ${ }^{[5]}$, which may lead to increasing symptoms and incidence of complications.

Many treatment modalities have already been used in the literature. The "wait and see" policy has been adopted, where it has been seen that spontaneous resolution of OME is common. In a study conducted by Tos et al., type B tympanometry showed improvement in $78 \%$ to $88 \%$ of cases with $\mathrm{OME}^{[6]}$.

On the contrary, the OME resolution rate at 6 months is only $26 \%$ and by 1 year it reaches only $33 \%{ }^{[6]}$, which yields few chances for higher resolution rates with longer periods of waiting time, which provide more chances for possible complications.

Medical treatments that have been used in the literature include antibiotics ${ }^{[7]}$, steroids with antibiotics ${ }^{[8]}$, and antihistamine ${ }^{[9]}$. Due to increasing antibiotic resistance and the presumed side effects of medications, however, the use of medicinal treatment only remains controversial.

Myringotomy and ventilation tube insertion are the most commonly used methods in treating children with chronic otitis media with effusion (COME). There are 
many reports in the literature documenting that timely ventilation tube insertion can relieve the symptoms of OME and prevent its complications ${ }^{[10]}$. Complications associated with myringotomy and ventilation tube insertion, however, have been shown to reach approximately $80 \%$ of operating ease in some paediatric age groups. These complications include otorrhoea, myringosclerosis, segmental atrophy, scars, granulations, retraction pockets, and ear drum perforations ${ }^{[11]}$.

To avoid these complications, myringotomy and ventilation tube insertion should be reserved only for selected cases where children are exposed to environmental infections, children have bilateral hearing loss of 25 decibels or more for at least 12 weeks, children have bilateral effusion for an additional 6 months, and children have unilateral effusion for at least an additional 9 months ${ }^{[12]}$.

Today, myringotomy is rarely performed alone, without the insertion of ventilation tubes. Mandel et al. in their study documented that myringotomy alone does not serve as a better cure than conservative measures regarding the number of attacks of acute otitis media (AOM), the number of subsequent needed surgeries, or the duration of middle ear effusion ${ }^{[13]}$.

In this study, the aim was to compare the outcomes of myringotomy with grommet tubes versus myringotomy without grommet tubes in cases with serous COME as regards hearing outcomes, rate of recurrence of effusion, and possible complications to assess the necessity of inserting grommet tubes to treat this particular condition.

\section{PATIENTS AND METHODS}

A prospective randomized study was conducted on paediatric patients of 12 years old or younger who presented with COME to the outpatient clinic of the department of otorhinolaryngology in one of the largest institutes in the country between July 2016 and June 2018. Local hospital ethical committee approval was obtained, as was signed informed consent from the guardian(s) of each child to be included in the study.

Cases were considered chronic after a time period of 3 months with no resolution of type B or Cs tympanometry. All cases presenting with a hearing gap of an average loss of at least 25 decibels were included in the study. Cases were subjected to either post nasal space X-ray or endoscopic examination, according to their cooperation, to assess adenoid hypertrophy. All cases included in the study had various grades of adenoid hypertrophy. All cases underwent adenoidectomy and bilateral myringotomy. The study was intended for cases with serous thin, not viscid, effusion in the middle ear, as seen at the time of myringotomy. On an alternate patient basis, grommet tubes were either inserted or not. Postoperatively, cases were advised to avoid ear wetting. The patients were divided into 2 equal groups. The patients in group A underwent bilateral myringotomy with grommet tube insertion, while the patients in group B underwent bilateral myringotomy only.

The inclusion criteria were as follows

1- Paediatric age group, 12 years of age or younger.

2- Chronic otitis media with effusion with no resolution after a period of time not less than a 3-month duration.

3- A conductive hearing loss of not less than 25 decibels.

4- Persistent tympanometry test of either type B or Cs result.

5- Serous effusion only, as seen at the time of myringotomy.

The exclusion criteria were as follows:

1- Older than 12 years of age.

2- Any improvement of middle ear effusion during the first 3 months of the disease.

3- Mixed hearing loss.

4- Cases of cleft palate, congenital craniofacial diseases, and coagulation problems.

5- Mucoid effusion, as seen at the time of myringotomy.

All patients were compared regarding demographic presentation of age and gender. The degree of preoperative conductive hearing loss (air-bone gap) and postoperative hearing gain, which referred to the improvement of air bone gap thresholds after the operation, were compared between the 2 groups. Presence or absence of otorrhoea was monitored and compared between the 2 groups. A repeat tympanometry was performed 9 months after the procedure to evaluate recurrence, if any, where types $\mathrm{A}$ and $\mathrm{C}$ were considered as resolution of effusion, while grades Cs and $\mathrm{B}$ were considered as recurrence of the disease. Otoscopic examination was performed to assess and compare the 2 groups as regards myringosclerosis (hyalinization and calcification of the tympanic membrane), which appeared as whitish patches in the tympanic membrane.

\section{Statistical analysis}

Qualitative data were presented as numbers and percentages. Quantitative data were presented as means and standard deviations. Comparisons between the 2 groups were made using the chi-square test for qualitative data and the independent t-test for quantitative data. Statistical significance was determined as $P<0.05$, while a highly significant difference was calculated as $P<0.001$, using SPSS, version 21 (SPSS Inc., Chicago, USA).

\section{RESULTS}

Patients in group A underwent bilateral myringotomy with insertion of bilateral grommet tubes, while patients in group B underwent bilateral myringotomy only. The average age of patients in group A was $6.865 \pm 1.99$ years old, while the average age of patients in group B was $5.97 \pm 2.1$ years old, with no statistically significant 
difference ( $\mathrm{P}$ value 0.064). In group $\mathrm{A}$, there were 18 boys and 19 girls, while in group B there were 19 boys and 18 girls, with no statistically significant difference ( $P$ value 0.816 ) between the 2 groups (Table 1 ).

Comparing the preoperative average hearing loss revealed that there was no statistically significant difference in the right ear or left ear average air bone gap between the 2 groups (Table 2).

Hearing gain 3 months after the procedure was compared between the 2 groups. There was no statistically significant difference between the 2 groups as regards the hearing gain thresholds in either the right or left ears (Table 2).

Myringosclerosis was noticed in 4/37 cases in group A, while no cases were encountered in group $\mathrm{B}$, with a significant statistical difference (Table 3).

Otorhhoea incidence was compared between the 2 groups. It happened in 6/37 in group A and 0/37 in group B, with a $P$ value of 0.011 indicating a significant difference between the 2 groups (Table 4 ).

Tympanometry after an average period of 9 months after the operation was compared after the healing of the ear drum in group B and extrusion of the grommet tubes in group A after the healing of the ear drum (Table 5), where type Cs was considered a recurrence of otitis media with effusion. There were 2 cases with left-ear recurrence in the no-grommet group versus no left-ear recurrence in the grommet group, whereas there was 1 case with rightear recurrence in the grommet group versus no right-ear recurrence in the no-grommet group, with no statistically significant difference.

Table 1: Demographic data of both groups

\begin{tabular}{lcccc}
\hline & & Group A with grommet & Group B without grommet & $P$ value \\
\hline Age & & $6.865 \pm 1.99$ years & $5.97 \pm 2.1$ years & 0.064 \\
\multirow{2}{*}{ Gender } & Males & 18 & 19 & 0.816 \\
& Females & 19 & 18 & \\
\hline
\end{tabular}

Table 2: Degree of hearing loss $(\mathrm{dB})$ and postoperative hearing gain with the statistical correlation between the 2 groups.

\begin{tabular}{lcccc}
\hline & Group A with grommet & Group B without grommet & Total & $P$ value \\
\hline Right ear hearing gap & $28.27 \pm 3$ & $28.35 \pm 4$ & $28.31 \pm 3.5$ & 0.922 \\
Left ear hearing gap & $28 \pm 3.16$ & $28.19 \pm 3.71$ & $28.095 \pm 3.4$ & 0.814 \\
Right ear hearing gain & $24.35 \pm 3.36$ & $24.65 \pm 3.47$ & $24.5 \pm 3.39$ & 0.709 \\
Left ear hearing gain & $24.32 \pm 3.22$ & $24.81 \pm 3.67$ & $24.57 \pm 3.44$ & 0.546 \\
\hline
\end{tabular}

Table 3: Myringosclerosis count, percentage, and $\mathrm{P}$ value in groups A and $\mathrm{B}$.

\begin{tabular}{lcccc}
\hline & & Group A with grommet & Group B without grommet $P$ value \\
\hline & No & Count & 33 & 37 \\
Myringoscelrosis & \% within groups & $89.2 \%$ & $100.0 \%$ & 0 \\
& Yes & Count & 4 & 0.04 \\
\hline
\end{tabular}


Table 4: Count, percentage, and statistical correlation between the 2 groups as regards the incidence of otorrhoea

\begin{tabular}{|c|c|c|c|c|c|}
\hline & & & Group A with grommet tube & Group B without tube & $P$ value \\
\hline \multirow{7}{*}{ Otorrhoea } & & Count & 31 & 37 & \\
\hline & No & & & & \\
\hline & & $\%$ within groups & $83.8 \%$ & $100.0 \%$ & \\
\hline & & & & & 0.011 \\
\hline & & Count & 6 & 0 & \\
\hline & Yes & & & & \\
\hline & & $\%$ within groups & $16.2 \%$ & $0.0 \%$ & \\
\hline
\end{tabular}

Table 5: Bilateral tympanometry findings (type Cs considered as recurrence) in both groups as count and P value

\begin{tabular}{|c|c|c|c|c|c|}
\hline & & Type A & Type C & Type Cs & $P$ value \\
\hline \multirow{3}{*}{ Left ear } & With grommet & 26 & 11 & 0 & \multirow{3}{*}{0.328} \\
\hline & & & & & \\
\hline & Without grommet & 23 & 12 & 2 & \\
\hline \multirow{3}{*}{ Right ear } & With grommet & 26 & 10 & 1 & \multirow{3}{*}{0.548} \\
\hline & & & & & \\
\hline & Without grommet & 25 & 12 & 0 & \\
\hline
\end{tabular}

\section{DISCUSSION}

Otitis media with effusion remains one of the most common ear diseases in the childhood period. Cases are considered chronic after 3 months of failed resolution or if the attacks recur 6 times or more in 12 consecutive months ${ }^{[4]}$.

OME is more prevalent under 2 years of age, but its prevalence peaks again at the age of 5 years old, which approximates the result obtained for both groups in this study. It may present to the physician 2 years after the initial expression of family concern ${ }^{[14]}$.

There is no gender difference regarding incidence of $\mathrm{OME}^{[15]}$. This observation from the literature concurs with the results of this study.

In the literature, some studies have observed no significant association between adenoidectomy and recurrence of OME, observing that a lack of statistical power can be seen ${ }^{[16]}$, while other studies have found that the absence of adenoidectomy is the chief factor in the recurrence of $\mathrm{OME}^{[17]}$. Despite controversies, there is a serious relation between adenoid vegetations, which obstruct the Eustachian tube, and $\mathrm{OME}^{[18]}$.

In all cases in the present study, adenoidectomy was performed regardless of the grade of hypertrophy detected by either the endoscopic method or post nasal space
X-ray. This was done to exclude the impact of adenoid hypertrophy on Eustachian tube function in both groups and to prevent the possible spread of infection from the adenoid tissue to the middle ear mucosa.

Different grades of conductive hearing loss can be caused by this condition, depending on whether the effusion is serous or mucoid ${ }^{[19]}$. Hearing loss can range from 15-40 decibels $(\mathrm{dB})^{[20]}$. The average hearing thresholds seen in children with OME are 27.8 decibels $^{[21]}$. This observation from the literature concurs with the results of this study, where there was no statistical difference in conductive hearing loss between the 2 groups or between right and left ears in the same group.

Selection criteria in this study followed the recommendations of Rovers et al. for myringotomy and grommet tube insertion ${ }^{[12]}$.

Early in the disease process, when the fluid in the middle ear is serous, lower symptom intensity is recorded. With increased duration and chronicity of the disease, serous fluid will change into more mucoid forms and atelectatic changes of the intact ear drum will appear, resulting in the formation of retraction pockets with consequent complications and increased hearing $\operatorname{loss}^{[20]}$.

The postoperative hearing gain was compared between the 2 groups to evaluate which method yields better hearing results. In this study, both techniques improved the hearing 
thresholds of patients, without statistical difference.

In a study in the UK, average hearing gain 6 months after the operation was approximately $9 \mathrm{~dB}$ when grommets were inserted alone, without adenoidectomy ${ }^{[22]}$.

In a systematic review to compare the effectiveness of grommet insertion versus myringotomy or conservative measures in children with OME, either in randomized patients or in randomized ears, it was found that the mean hearing level gain was approximately $12 \mathrm{~dB}$ more in grommet ears than in control ears in a study of randomized patients and approximately $10 \mathrm{~dB}$ more in grommet ears than in control ears in a study of randomized ears ${ }^{[23]}$. The researchers mentioned, however, that this hearing gain decreases with time and becomes comparable and nearly equal to the hearing gain of untouched controls on conservative measures or myringotomy alone. This study documented that the hearing gain 3 months after the operation was nearly the same in both groups, with no statistical difference.

An interesting finding concerns the conductive gap that remained even after grommet tubes were inserted, especially in the first 3 months after the procedure, which might be attributable to some mucosal edema around the ossicles due to chronic irritation by the fluid in the middle $\operatorname{ear}^{[24]}$.

In this study, this residual conductive gap was smaller, and this is mostly related to the type of fluid and, consequently, the lower levels of irritation and inflammation around the ossicular chain.

Several studies in the literature found that myringotomy and ventilation tube insertion offered more time with no effusion and better hearing than myringotomy alone $^{[25,26,13]}$. In this study, no statistical difference existed between the 2 groups regarding recurrence of the condition, which suggests that the no-tube option gave near equal results to the results enjoyed by the tube group.

In their study, Vlastarakos et al. found that the rate of myringosclerosis reached $39-65 \%$ of cases $^{[11]}$. Dempster et al., in their study in 1993, reported the presence of myringosclerotic patches in $38 \%$ of ears that had previously had a grommet tube inserted compared to $1 \%$ of ears with no grommets ${ }^{[27]}$. These findings concur with the results of this study.

As regards otorrhoea, the rates after myringotomy tube insertion reached $10-26 \%$ of cases in the study conducted by Vlastarakos et al. ${ }^{[11]}$. Meanwhile, in the study conducted by Rovers et al., where the children were much younger, cases with otorrhoea reached approximately $49 \%$ in grommet ears and $10 \%$ in non-grommet ears ${ }^{[28]}$. These findings concur with the results of this study. This might be explained by the lower chance of infection after healing of the myringotomy in group B compared to the higher chance of infection with the patency of the tubes and longer duration of stay in the ear drums, which might not be needed in the serous type of middle ear effusion.

Adenoidectomy itself might be a reason for the cure of this condition; thus, another study, including only adenoidectomy without myringotomy, might be conducted in the future to assess the effect of adenoidectomy on this condition.

\section{CONCLUSION}

In serous otitis media with effusion-where, despite its chronicity and the failure of medical treatment, symptoms are less severe than in the mucoid type-it may be advisable to use a less invasive surgical measure, such as myringotomy without the insertion of grommet tubes. It provides equal hearing gain and a near equal rate of recurrence of effusion, with lower incidence of complications such as otorrhoea and myringosclerosis.

Longer follow-up on these cases might also be needed to evaluate the impact of both solutions after 1 year and 2 years from the surgery date.

\section{CONFLICT OF INTEREST}

There are no conflicts of interest.

\section{CONFLICT OF INTEREST}

Author would like to thank Dr. Enas M. Fawzy, Head of Biostatistical department, National Nutrition Institute, Cairo, Egypt for her help in the statistical part of the study.

\section{REFERENCES}

1. Rosenfeld RM, Schwartz SR, Pynnonen MA, et al. Clinical practice guideline: tympanostomy tubes in children. Otolaryngol Head Neck Surg. 2013;149 (suppl 1).

2. Elicora SS, Ozturk M, Sevinc R,et al. Risk factors for otitis media effusion in children who have adenoid hypertrophia. Int J Pediatr Otorhinolaryngol. 2015;79(3):374-377.

3. Tos M. Epidemiology and natural history of secretory otitis. Am J Otol. 1984;(6):459-462.

4. Kenna, MA. Otitis media and the new guidelines. J Otolaryngol. 2005;34 (suppl 1):S24-32.

5. Zernotti ME, Pawankar R, Ansotegui I, et al. Otitis media with effusion and atopy: is there a causal relationship? World Allergy Organ J. 2017;10(1):37. 
6. Tos M, Holm-Jensen S, Sorensen $\mathrm{CH}$, et al. Spontaneous course and frequency of secretory otitis media in 4-year-old children. Arch Otolaryngol Head Neck Surg. 1982;108.

7. Mandel EM, Casselbrant ML. Antibiotics for otitis media with effusion. Minerva Pediatr. 2004;56:481.

8. Butler CC, van der Voort JH. Steroids for otitis media with effusion. Arch Pediatr Adolesc Med. 2001;155:641- 647 .

9. Witmer A, Wells AM, Seymour RJ. A comparison of the effectiveness of pharmacologic treatment of otitis media with effusion in children: integrative and metaanalysis. Online J Knoml Synth Nurs. 1998;5(4).

10. Chow Y, Wabnitz DA, Ling J. Quality of life outcomes after ventilating tube insertion for otitis media in an Australian population. Int J Pediatr Otorhinolaryngol. 2007;71(10):1543-1547.

11. Vlastarakos PV, Nikolopoulos TP, Korres S., et al. Grommets in effusion: the most frequent operation in children. But is it associated with significant complications? Eur J Pediatr. 2007;166:385-391.

12. Rovers MM, Black N, Browning GG, et al. Grommets in otitis media with effusion: an individual patient data meta-analysis. Arch Dis Child. 2005;90:480-485.

13. Mandel EM, Rockette HE, Bulestone CD, et al. Myringotomy with and without tympanostomy tubes for chronic otitis media with effusion. Arch Otolaryngol Head Neck Surg. 1989;115(10).

14. Maw AR, Tiwari RS. Children with glue ear: how do they present? Clin Otolaryngol. 1988;13:171-177.

15. Atkinson $\mathrm{H}$, Wallis $\mathrm{S}$, Coatesworth AP. Otitis media with effusion. Postgrad Med. 2015;127(4):381-385.

16. Wallace IF, Berkman ND, Lohr KN, et al. Surgical treatments for otitis media with effusion: a systematic review. Pediatrics. 2014;133:296-311.

17. Boston M, McCook J, Burke B, et al. Incidence of and risk factors for additional tympanostomy tube insertion in children. Arch Otolaryngol Head Neck Surg. 2003;129:293-296.

18. Sanli A, Tasdemir O, Eken M, et al. Prevalence of otitis media with effusion among primary school age-children and etiopathogenic examination.
Indian J Otolaryngol Head Neck Surg. 2011;66 (suppl 1):95-98.

19. Gravel JS, Wallace IF. Effects of otitis media with effusion on hearing in the first 3 years of life. J Speech Lang Hear Res. 2000;43(3):631-644.

20. Madell JR. Impact of otitis media on auditory function. In Rosenfeld RM, Bluestone CD, eds. Evidence-based otitis media. Canada: B.C. Decker Inc; 1999;337-351.

21. Butler CC, van der Voort JH. Oral or topical nasal steroids for hearing loss associated with otitis media with effusion in children. Cochrane Database Syst Rev. 2000;CD001935.

22. Multicentre, Council Media, Otitis Group, S. Surgery for persistent otitis media with effusion: generalizability of results from the UK trial (TARGET). Clin Otolaryngol Allied Sci. 2001;26:417-424.

23. Browning GG, Rovers MM, Williamson I, et al. Grommets (ventilation tubes) for hearing loss associated with otitis media with effusion in children. Cochrane Database Syst Rev. 2010;10(1801).

24. Caye-Thomasen P, Stangerup SE, Jorgensen G, et al. Myringotomy versus ventilation tubes in secretory otitis media: eardrum pathology, hearing, and Eustachian tube function 25 years after treatment. Otology and Neurotology. 2008;29(5):649-657.

25. Gates GA, Wachtendorf C, Hearne EM, et al. Treatment of chronic otitis media with effusion: results of tympanostomy tubes. Am J Otolaryngol. 1985;6:249-253.

26. Gates GA, Wachtendorf C, Hearne EM, et al. Treatment of chronic otitis media with effusion: results of myringotomy. Auris Nasus Larynx. 1985;12 (suppl 1):S262-S264.

27. Dempster JH, Browning GG, Gatehouse SG. A randomized study of the surgical management of children with persistent otitis media with effusion associated with a hearing impairment. Journal of Laryngology and Otology. 1993;107(4):284-289.

28. Rovers MM, Straatman H, Ingels $\mathrm{K}$, et al. The effect of ventilation tubes on language development in infants with otitis media with effusion: a randomized trial. Pediatrics. 2000;106(3):42(1-8). 